\title{
Research on the Coordination Relationship between Basic Public Service Expenditure and Economic Development Level Based on the Data of 31 Provinces from 2000 to 2016
}

\author{
Xinyu Zhang* \\ School of Marxism \\ Dalian University of Technology \\ Dalian, China \\ 996173141@qq.com
}

\author{
Xiaoshen Cai \\ Faculty of Humanity and Social Science \\ Dalian University of Technology \\ Dalian, China \\ cxshen99@163.com
}

\begin{abstract}
Based on entropy method for weight determination and introduced coordination degree and the coordinate development index model, the evaluation index system of coordination degree is constructed by taking 31 provinces from 2000 to 2016 as the research object. Then, the evaluation index system of coordination degree is used to empirically research the status of basic public service expenditure and economic development level. The result shows that the index of coordinated development is increasing year by year, but there is still a certain degree of imbalance between basic public service and economic development, and the gap shows a spindle-shaped change trend.
\end{abstract}

Keywords-basic public service expenditure; economic development; index of coordinated development

\section{INTRODUCTION}

Since the reform and opening up, China's national economic competitiveness has been improved by leaps and bounds, as well as the scale and quality of basic public services. However, at present, there are still some problems of inconsistent development between basic public service expenditure and economic development level, which are not conducive to social harmony and stability. Therefore, exploring the coordination relationship between basic public service expenditure and economic development level is of great significance not only for the implementation of the concept of "sharing" of public services, but also for the formulation of regional policies.

Existing studies mostly use coupling coordination model and decoupling model to discuss the interaction or coordination difference between basic public service expenditure and economic development level. Most of them take a province or region as the research unit ${ }^{[1-4]}$, and most of the data are crosssectional data of a year ${ }^{[1,4-6]}$. However, few studies have been conducted on the trends of the two over a longer period of time in the whole country. Based on the data of 31 provinces and regions (excluding Hong Kong, Macao and Taiwan)in China from 2000 to 2016, this paper will study the coordination relationship between basic public service expenditure and economic development level. By constructing the evaluation index system of coordination degree between basic public service expenditure and economic development level, using the entropy method, the coordinated status will be quantitatively measured in 31 provinces from 2000 to 2016.

\section{A. Index Selection and Data Source}

This paper introduces the evaluation of coordinated development index to evaluate the coordination relationship. The evaluation index of coordination relationship is constructed as followed. In terms of basic public services, the key indicators of basic public services in the National Basic Public Service List of the 13th Five-Year Plan are adopted, including public education, employment and entrepreneurship, social insurance, medical and health care, social services, housing security, public cultural and sports, and services for the disabled. In terms of economic development, the main indicators at home and abroad are adopted, including public education, employment and entrepreneurship, social insurance, medical and health services, housing security, public cultural and sports, economic aggregate, economic growth rate, economic extroversion, economic benefit, economic motive force, etc. ${ }^{[7-8]}$, the indicators are detailed in Table 1 . Secondly, the data in this paper are from China Statistical Yearbook from 2000 to 2017.

TABLE I. EVALUATION INDEX OF COORDINATION RELATION

\begin{tabular}{|l|c|c|}
\hline & Index & Weight \\
\hline \multirow{4}{*}{ Basic public service expenditure } & Public education expenditure & 0.08 \\
\cline { 2 - 3 } & Social security and employment expenditure & Ten thousand Yuan \\
\cline { 2 - 3 } & Expenditure on health care and family planning & Ten thousand Yuan \\
\cline { 2 - 3 } & Cultural sports and media expenditure & Ten thousand Yuan \\
\hline
\end{tabular}

Supported by Basic Research Business Fee Project of Dalian University of Technology (DUT17RW216) 


\begin{tabular}{|c|c|c|c|}
\hline \multicolumn{4}{|c|}{ Cont. to TABLE I } \\
\hline \multirow{6}{*}{ Economic development level } & Total GDP & Billion Yuan & 0.08 \\
\hline & Annual growth rate of GDP & $\%$ & 0.06 \\
\hline & Per capita GDP & Yuan / person & 0.20 \\
\hline & Average GDP & Ten thousand Yuan per square kilometer & 0.01 \\
\hline & Number of patent applications & Piece & 0.16 \\
\hline & Total investment amount of foreign-funded enterprises & Ten thousand dollars & 0.15 \\
\hline
\end{tabular}

\section{B. Research Method}

\section{1) Index Measurement Based on Entropy Method}

After standardizing the indicators, this paper calculates the weight coefficients of each index by using the entropy method, and obtains the overall scores of basic public service expenditure and economic development level respectively, as shown in Table I. Then, this paper calculates the coordinated development index.

2) Index Measurement Based on Entropy Method

This paper uses the evaluation model of coordinated development index to quantitatively analyze the coordination relationship between basic public service expenditure and economic development level. The main formulas are as follows:

$$
\begin{aligned}
C & =\left\{U 1 \times U 2 /[(U 1 \times U 2) \div 2]^{2}\right\}^{K} \square \\
T & =\alpha U 1 \times \beta U 2 \\
D & =\sqrt{C \times T}
\end{aligned}
$$

Among them, $K$ is the number of subsystems, $T$ is the comprehensive coordination index of basic public service expenditure and economic development level; $D$ is the coordinated development index, and the value of $D$ is between $0-1$; $C$ is the coupling degree; $\alpha$ and $\beta$ are the undetermined coefficients. This paper considers that basic public service expenditure and economic development level are very important, so $\alpha=\beta=0.5$; $U 1$ and $U 2$ are comprehensive scores of the subsystems of basic public service expenditure and economic development level.

\section{Measurement of CoORdinAtion Relations}

By calculating the coordinated development index of basic public service expenditure and economic development level in 31 provinces in China from 2000 to 2016, and using the median subsection method ${ }^{[6-8]}$, the coordinated development index is divided into four types: $0-0.3$ is the stage of low coordinated development, $0.3-0.5$ is the stage of moderate coordinated development, $0.5-0.8$ is the stage of high coordinated development, and $0.8-1$ is the stage of extreme coordinated development. The quantitative results are analyzed as follows.

This paper takes the coordinated development index to measure the coordinated relationship between basic public service expenditure and economic development level, and to observe the changes of the relationship between the two at different stages.

Overall, the coordinated development index curve of basic public service expenditure and economic development level has been on the upward trend from 2000 to 2016, and the value is increasing year by year (as shown in Figure 1). This shows that the relationship between basic public service expenditure and economic development level is gradually moving towards coordination and optimization. According to the type of coordinated development index, it can be divided into three sections.

The first stage is the stage of low-level coordinated development (2000-2007). During this period, although the coordinated development index gradually increases, the growth rate tend to be very slow, and the index is lower than 0.3 all during this period of time, so it belongs to the stage of low coordinated development. This may be related to the focus of national construction. In the first two decades of this century, the main task of reform is to build a sound socialist market economic system and economic system. Especially after China's entry into WTO, China's economy has entered a new stage of participating in global competition. At this time, the focus of our country's work is to achieve rapid economic development through economic restructuring, and governments at all levels invest in basic public services. Limited energy input has resulted in a serious lag in expenditure on basic public services compared with the level of economic development at this stage.

The second stage is the stage of moderate coordinated development (2008-2011). The index of coordinated development made a leap in 2008. During this period, the index of coordinated development showed a steady growth trend, and the growth rate was significantly increased compared with the previous stage. The sharp increase of the coordinated development index is closely related to the adjustment of policy orientation. After the 16th National Congress, China's financial system reform promote the equalization of basic public services and the construction of main functional areas as the basic policy. Governments at all levels constantly adjust and optimize the structure of fiscal expenditure on the basis of supporting economic development and expanding the "cake" of fiscal revenue. In February 2008, the State Council promulgated the construction concept of the basic public service system, and proposed that the construction of the basic public service system should be based on economic development, and gradually realize the equalization of basic public service according to the level and degree of economic development. Under the guidance of the new policy, basic public services have achieved all-round development, mainly in the following aspects:

- In housing security, emphasis is laid on building a housing security system. The Ministry of Finance, the State Administration of Taxation, the Ministry of Housing and Urban-Rural Construction and other departments have issued a number of guidelines to strengthen low-rent housing and affordable housing. The State has added 7.5 billion Yuan to the 
construction of low-rent housing, accounting for $7.5 \%$ of the total new investment in four quarters.

- Medical and health reform has become an important key word in people's livelihood policy. The opinions on deepening the reform of medical and health system were published in October 2008 and asked for public opinions.

- In the area of public education, from September 1, 2008, incidental fees for urban compulsory education were exempted nationwide.

- In the area of poverty alleviation through social security, the Ministry of Civil Affairs, in conjunction with relevant departments, has twice raised the subsidy level for urban low-income people. In this year, the central government spent 26.6 billion Yuan on subsidizing local urban low-income people, an increase of 10.6 billion Yuan over 2007.

At the same time, 2008 is a year of frequent snowstorms, floods and earthquakes. Sudden natural disasters have brought heavy losses to the national economy and people's lives. Special requirements in special periods have also become one of the important impetus to strengthen the construction of basic public services. The Central Economic Work Conference emphasized that improving people's livelihood should be the starting point and the foothold of ensuring growth. The Ministry of Finance clearly calls for promoting the transformation of the mode of economic development, making every effort to reduce general financial expenditure, devoting more resources to solving the difficulties of people's production and life, increasing investment in areas closely related to people's lives, and vigorously strengthening the construction of people's livelihood services. Under the guidance and promotion of relevant policies such as economic restructuring and basic public service construction, the focus of provincial and regional governments has shifted from focusing solely on economic growth to ensuring the most concerned, direct and realistic interests of the people, striving for regional development in the balance of economy and society, thus reversing the long-term lag of expenditure on basic public services over the economy development level, which promotes the formal progress of the relations to the stage of moderate coordinated development.

The third stage is the stage of highly coordinated development (2012-2016). The growth rate of the coordinated development index in this period is basically the same as that in the second stage. China's basic public service expenditure and economic development level have been coordinated and integrated, showing a good trend of coordinated development. The scientific concept of people-oriented, comprehensive, coordinated and sustainable development promotes the allocation of the relationship between basic public service expenditure and the level of economic development. Local governments pay more attention to strengthening the construction of basic public service, and regard meeting the basic public service needs of the people as the key work of public financial management.

Under the guidance of relevant policies, various regions have issued plans of action for equalization of basic public services, actively promoting the construction of public service system shared by the whole people, so as to speed up the social construction focusing on improving people's livelihood. In July 2012, the State Council issued the "Twelfth Five-Year Plan" for the National Basic Public Service System, which clearly calls for the establishment and improvement of the basic public service system. This marks the issuance of the guiding document for the construction of basic public services. Since then, the development of basic public services has developed a normative framework. With the support of the policies of the central and local governments, the expenditure on basic public services and the level of economic development have been improved. Relations have gradually been coordinated and entered a new stage of highly coordinated development.

\section{ANALYSIS OF LAG PHENOMENON}

Although the curve of expenditure on basic public services and the curve of economic development level in China are both on the rise, the gap between them persists obviously in terms of quantity comparison. From Figure 1, before 2007, the expenditure curve of basic public services tended to be flat, and the growth rate was negligible, while the level of economic development remained stable at a rate of 3\%. Because of the inconsistency between the two curves, the gap between the two curves is gradually widening. Since 2008, the expenditure curve of basic public services has risen rapidly, with an annual growth rate of 3.9\%, and the level of economic development has steadily increased by an average annual growth rate of $5 \%$. The convergence and closeness of the two curves shows that the development gap between the two curves is gradually narrowing. After 2015, as the economic development level has increased significantly, the gap between the two is widened again, and the two curves show a trend of separation. Generally speaking, the curve of basic public service expenditure and the curve of economic development form a spindle shape, and the gap between the two has undergone an N-type change process of increasing first, then narrowing and then increasing.

From the lag curve of basic public service expenditure (see Fig. 1), we can clearly see the lag of basic public service expenditure. From 2000 to 2007, the lag of basic public services has been increasing all the time. After 2007, the lag of basic public services shows a trend of fluctuation and decline, and continues to shrink at an annual average rate of $1 \%$. After 2015, the lag curve has risen again. This shows that although the gap between basic public services expenditure and economic development level has been narrowed, there is still room for improvement in the coordination. 


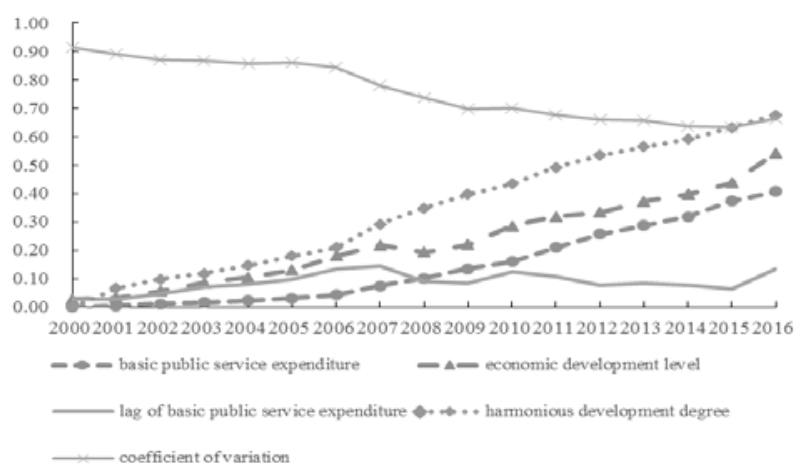

Fig. 1. Trend of basic public service expenditure and economic development level

The inability of basic public service expenditure to adapt to the level of economic development in terms of quantity and scale is mainly related to policy bias, financial system and performance appraisal system. In terms of policy, in order to create more wealth and provide a solid material basis for the socialist system, the 10th Five-Year Plan puts forward the development task of "establishing strategic adjustment of economic structure as the main line in accordance with the needs of developing socialist market economy", and policy formulation mainly supports economic construction. In terms of financial system, $75 \%$ of VAT was collected by the central government after the reform of tax distribution system. The pressure of local financial expenditure increased, and the local government's ability to construct basic public services was relatively limited. In terms of performance appraisal system, the economic indicators represented by GDP account for the main proportion in local performance appraisal. Influenced by the "promotion championship" mechanism, the most important goal of local governments is economic growth, while public service preferences are usually weak. Under the constraints of established resources, excessive emphasis on GDP and pursuit of economic growth will inevitably squeeze into the financial expenditure of building basic public services. Restricted by policy support and financial capacity, there has been a longterm imbalance between basic public services and economic development. If the government do not pay attention to the coordinated promotion of the two, the barrel capacity of development will be limited, and the process of building a well-off society in an all-round way will be hindered.

\section{CONCLUSION}

By studying the coordination relationship between basic public service expenditure and economic development level in provinces from 2000 to 2016, this paper draws the following conclusions:

- On the whole, the coordinated development index shows an increasing trend year by year, which indicates that the coordinated relationship between the two has been improved gradually.

- Basic public service expenditure lags behind economic development in terms of both quantity and growth rate. The gap between the two shows a spindle-shaped trend of change, which increases gradually at first and then decreases gradually. The situation of coordinated development has not yet formed.

Based on the above conclusions, this paper suggests that:

- Continue to increase the scale of expenditure on basic public services and avoid short-sighted acts of crowding out expenditure on basic public services for the development of local economy.

- Promote cooperation between the government and social capital, and open up some basic public service projects to private capital and foreign capital, and attract social capital from the fields of education, health care, pension and public culture.

- Speed up the establishment of official performance appraisal and administrative accountability system with the construction of basic public services as the main indicators, and improve the supervision system of basic public services.

\section{REFERENCES}

[1] Cai Xiuling and Qiao Shuhao, "Analysis on the coupling and coordination degree of basic public service expenditure and economic development level in Fujian province,” Fujian Tribune, vol. 7, pp. 146158, July 2017.(In Chinese)

[2] Wang Junxia, Gao Fei, and Zhu Danfeng, "Coordinated development of urban and rural economy and equalization of basic public servicesanalysis based on coupling and coordination model," East China Economic Management, vol. 8, pp. 36-42, July 2015.(In Chinese)

[3] Liu Chuntao, Han Zenglin, Gong Yuanshan, and Peng Fei, "Evaluation of coordination degree between economic development and basic public services in Bohai rim,” Resource Development and Market, vol. 31, pp. 1052-1056, September 2015.( in Chinese)

[4] Lin Guangxiang, Lu Tao, and Penglu, "Discussion on the relation between basic public service expenditure and regional economic coordination in Guangxi,” Regional Research and Development, vol. 9, pp. 22-28, March 2017. (In Chinese)

[5] Cuadrado-Ballesteros, Garcia-Sanchez, and Prado-Lorenzo, "Effect of modes of public services delivery on the efficiency of local governments: A two-stage approach,” Utilities Policy, vol. 26, pp. 23-25, May 2013.

[6] Ács Z J, Szerb L, and Autio E, “Global entrepreneurship and development index 2015,” Springer briefs in Economics, vol. 33, pp. 3964, September 2017

[7] Arvis J F, Saslavsky D, Ojala L, et al, "Trade logistics in the global economy: the logistics performance index and its indicators," World Bank Operational Studies, vol. 88, pp. 400, May 2016.

[8] Thiry G, "Beyond GDP: conceptual grounds of quantification-the case of the index of economic well-being (IEWB)," Social Indicators Research, vol. 121, pp. 313-343, February 2015. 